\title{
Implications for Collaborative Development of Reverse Distribution Network: A System Perspective
}

\author{
Yulia Lapko ${ }^{1}$, Paolo Trucco ${ }^{1}$, Andrea Trianni ${ }^{1}$, and Cali Nuur ${ }^{2}$ \\ ${ }^{1}$ Politecnico di Milano, Milan, Italy \\ \{yulia.lapko, paolo.trucco, andrea.trianni\}@polimi.it \\ ${ }^{2} \mathrm{KTH}$, Royal Institute of Technology, Stockholm, Sweden \\ cali.nuur@indek.kth.se
}

\begin{abstract}
One of the recurring challenges that industries and society face is the availability of and access to resources. The scarcity of resources creates instability in the supply chains of firms and in turn affects competitiveness. In recent years, the notion of a reverse distribution network has been put forth as a possible solution to remedy not only the volatility of the supply chains but also as an indispensable approach for sustainable development. This paper examines the current state of the literature on reverse distribution networks from a system perspective. Two major findings were identified. Firstly, there are no clear grounds for decision making regarding supply network development. Secondly, collaborations offers great opportunities to develop reverse distribution networks and build robust supply chains.
\end{abstract}

Keywords: resource scarcity, collaboration, reverse distribution network.

\section{Introduction}

Available research indicates increasing constrains on availability and production of resources $[1,2]$ as well as that resource scarcity is turning to be the major problem for many industries [3]. Economic growth and rapid increase of population impose great pressure on the supply of resources while at the same time, environmental and social cost of mining is increasing [2]. Several studies have discussed the problem of resource scarcity and have criticality assessed the role of raw materials on economic performance, supply risk, vulnerability to supply disruptions and ecological risks [4, 5]. They have highlighted how the scarcity of Critical Raw Materials (CRM) can become a bottleneck for deployment of emerging technologies (e.g., electronics and green energy) due to high geographical concentration of supply, low recycling rates and low (or even impossible) substitutability [6, 7, 8, 9]. Although technology plays important role for mitigation risks related to resource scarcity, there is a need for the supply chains that could ensure both resource efficiency and secure sources of their supply [10].

Reverse Distribution Network (RDN) has been proposed as a possible solution to offset the challenges related to resource scarcity [10]. RDN can be defined as the 
logistics structure for managing the backward flow of materials (from customers back to suppliers). RDN is also important since companies are required to engage into material recovery operations by governmental policies [11], downstream partners and other stakeholders [12]. Nevertheless, RDNs are the subject of a wide range of uncertainties, which create many obstacles for network development and maintenance. As a result, companies keep struggling to set up an efficient system [12, 13].

In order to gain understanding of such a complex phenomenon as RDN, it is important to take into consideration all elements within their interconnections. System perspective allows to meet this requirement. Adopting this perspective highlights two implications for RDN development (based on the systems theory [14, 15, 16]): consistency and complexity. Firstly, it is necessity to ensure consistency of the system through the pursuit of involved parties to the common (system) goal - maximization of the value creation (where value defined as the amount of recovered (recycled) materials). Secondly, complexity of RDN leads to decrease of the network agility. As $\mathrm{RDN}$ is a backbone solution for the problem of resource scarcity, it is necessary to ensure its adaptability to the changing environment.

Against this background, this paper aims at identifying the new prospects (new business opportunities, new forms of organization) for RDN development. It examines the existing knowledge base using the lens of the system perspective (enabling consistency and dealing with complexity).

Apart from this introduction, the paper is structured as follows. The subsequent section presents the methodology of the paper. In section 3, the results of the review are presented. The paper ends with conclusions and suggestions for further studies.

\section{Methodology}

To address the research aim, a literature review was performed. A sample of articles was selected from Scopus database using the following steps. An initial search using the four key words: 'green supply chain', 'closed loop supply chain', 'reverse logistics', 'product recovery network' was conducted on eight subject areas: engineering, business, management and accounting, decision science, environmental science, energy, economics econometrics and finance, material science, chemical engineering. The results were limited to academic articles from peer-reviewed journals. Only articles published after 1999 were considered, as at that time the EU started to shape new regulatory framework for companies' operations through new environmental-related directives, e.g., [11]. Moreover, according to the Scopus, the majority of research was developed after 1999, with a high attention from academia during last ten years. The relevance of the articles was evaluated in terms of their relation to resource scarcity mitigation and operating channel development, and was conducted through review of title and abstract in the first place. Afterwards, the selection was refined by reviewing the full texts of the articles. At the end, an examination of references cited in each relevant literature was performed in order to find additional sources of information. 


\section{$3 \quad$ Results}

Our results show that the literature, devoted to reverse distribution networks, can be divided in two streams: network design modelling and practical issues related to operating channel implementation. The former issues were discussed by [17], who summarized the addressed questions through number, location, type and capacity of recovery activities. Researches [18] examined networks in relation to a degree of centralization, number of levels, links with other networks, open vs closed loop structures, degree of branch co-operation. This stream of research mainly focuses on examination of structural, configuration issues of reverse distribution networks. It should be noted that existing models suffer several limitations and simplifications (e.g., considering only single-entity flow or only single reprocessing option), what makes developed models very specific. Models tend to use objective function to minimize costs of reverse distribution or maximize profit, what does not meet the necessity to pursue the system objective to maximize the value of returned items.

Another stream of research has more business orientation and deals with implementation of the reverse distribution networks. That stream is mainly represented by the following topics: collection of cores, remanufacturing activities and selection of suppliers and third party service providers. Researchers [19, 20] examine operating channels for collection activities arranged through different options (e.g., though Original Equipment Manufacturer (OEM), existing retailers from forward distribution, third party service providers and a joint venture). [21] proposed different strategies to acquire cores from customers (e.g., buy-back and voluntary based relationships). Great body of research is also dedicated to remanufacturing issues. Although researchers identify benefits of performing remanufacturing activities by (OEM) e.g., secured spare part supply [22] and balanced production lines [23] - there are still a lot of uncertainties and risks, like cannibalization of the sales for the OEM's new products, which lead to designing products to prevent remanufacturing [24]. Research in selection of suppliers and third party service providers is presented in different sets of criteria and algorithms that should be applied for estimation of a potential supplier/service provider [25].

Thus, it is worth noting that both streams of the literature were developed with focuses on different issues. Among the exceptions, we can mention studies of [26], who applied systems theory to formulate supply resiliency reducers; [27, 28], who developed constructs for successful collaborations in supply chains; [29] who presented a boundaries and flows perspective of green supply chain management; [30], who reviewed reverse logistics through inputs, processes and output; [24], who demonstrated the necessity to involve upstream actors for reverse operating channel development. Furthermore, little attention were paid to generalization of findings and developing guidelines for industries on how responsibilities should be divided in the network and which operating channel is suitable to every process. The latter issue is very important as many companies, that successfully implement forward logistics operations, have difficulties in efficient management of reverse direction of materials flows [12, 13].

There are few examples of OEMs that have integrated reverse logistics operations as a result of proactive planning measures, the majority is pushed by legislation to 
take responsibility for end-of-life products [11] or by requirements of a downstream partner and a stakeholder [12]. It is common, that OEMs tend to displace the burdensome processes through outsourcing of reverse logistics operations rather than involve them into their business models [12], [31]. This strategy leads to the loss of control of the further materials streams (strategic resources). Furthermore, it causes separation of decision-making and may lead to the conflicts of interests, as the decisions might not comply with the goal of the system in the whole and subsystem in particular. Therefore, problems of managing reverse flows also might be explained by lack of system consistency.

According to the systems theory, efficient operation of RDN depends on its consistency and complexity. Through the literature review, it was identified that both of them could be ensured through collaborations. Firstly, collaborations can help enable shared vision on the RDN development (pursuit to the common system goal), and secondly, they can help reduce uncertainties related to reverse flow operations thanks to collective creation and sharing of knowledge between involved parties. For example, according to the study [24], independent attempts of OEM to develop additional flows of resources through product recovery options can push suppliers to adjust resource/component prices, and eventually devalue OEM's activities to ensure supply and improve performance efficiency.

Supply chain collaboration means that "two or more independent companies work jointly to plan and execute supply chain operations with greater success then when acting in isolation" [27, p. 19]. Collaborations could be vertical, horizontal and lateral [27], all these types offer new prospects for development of RDN: collaborations between OEMs to perform reprocessing activities (horizontal), between OEM and suppliers to arrange a secondary resource flow (vertical), combination of previous examples would form a lateral collaboration.

Collaborative relationships as an important construct of an efficient supply chain performance has found support in several theories and perspectives [27], [32, 33]. For example, [34] considered supply chain collaborations from a transaction theory and resource based view. In addition, [35] discussed collaborations both from resource dependence theory and information theory, while [36] used the lens of resourceadvantage theory. Therefore, through collaboration it is possible to acquire necessary competences, to reach required level of trust and control between actors, to eliminate non-value-adding activities [33, 34], [37]. Moreover, [38] noted that collaborative initiatives help to share significant costs of establishment and maintenance of a recovery network as well as obtain required infrastructure and expertise. Collaborative development should help mitigate operations challenges of reverse flows, for example, by ensuring required capacity of flows from economic perspectives. Therefore, it is possible to consider collaborative development as an enabler and enhancer of building secondary streams of supply, what becomes increasingly important nowadays, when the problem of resource scarcity is raised. 


\section{Conclusion}

The aim of this paper was to identify the new prospects (new business opportunities, new forms of organization) for RDN development based on examination of existing knowledge base through the lens of system perspective (enabling consistency and dealing with complexity). Three major findings were highlighted.

Firstly, there is a gap in terms of providing a system picture of forward and reverse operations. There are different streams that focus on various particular issues without taking into consideration holism of the system and its consistency. Few efforts were put into generalization of findings and prescribing guidelines for industries on how the network should be developed in a stable way (papers have rather conceptual than practical orientation). The influence of the made decisions on performance efficiency of a system in the whole and its parts in particular requires further examination.

Secondly, the system perspective for RDN development highlights two implications: it is suggested to develop RDN to enable efficiency and effectiveness of the whole system rather than with orientation to the benefit of a particular stakeholder; it is necessary to develop RDN in a way to handle its complexity without following drawbacks for network adaptability.

Finally, it was identified that collaborative relationships can address requirements from both implications of the system perspective. They offer great opportunities to develop RDN. It is necessary to gain better understanding of creating new business opportunities, forms of organization and their influence on the system performance.

Acknowledgments. This paper is produced as part of the EMJD Programme European Doctorate in Industrial Management (EDIM) funded by the European Commission, Erasmus Mundus Action 1.

\section{References}

1. IEA: Energy technology perspectives 2008: scenarios \& strategies to 2050 (2008)

2. Prior, T., Giurco, D., Mudd, G., Mason, L., Behrisch, J.: Resource depletion, peak minerals and the implications for sustainable resource management. Glob. Environ. Chang. 22, 577-587 (2012)

3. PwC: Minerals and metals scarcity in manufacturing: the ticking time bomb (2011)

4. Achzet, B., Helbig, C.: How to evaluate raw material supply risks-an overview. Resour. Policy 38, 435-447 (2013)

5. Erdmann, L., Graedel, T.E.: Criticality of non-fuel minerals: a review of major approaches and analyses. Environ. Sci. Technol. 45, 7620-7630 (2011)

6. Department of Energy: Critical Mineral Strategy (2011)

7. European Commission: Critical raw materials for the EU. Report of the Ad-hoc Working Group on Defining Critical Raw Materials (2010)

8. European Commission: Report on critical raw materials for the EU. Report of the Ad-Hoc Working Group on Defining Critical Raw Materials (2014)

9. Moss, R.L., Tzimas, E., Kara, H., Willis, P., Kooroshy, J.: Critical Metals in Strategic Energy Technologies (2011) 
10. Krautkraemer, J.A.: Economics of Natural Resource Scarcity: The State of the Debate. Resour. Futur. (2005)

11. Directive 2000/53/E: Directive 2000/53/EC on End-of-Life Vehicles. Off. J. Eur. Union (2000)

12. Bai, C., Sarkis, J.: Flexibility in reverse logistics: a framework and evaluation approach. J. Clean. Prod. 47, 306-318 (2013)

13. Govindan, K., Palaniappan, M., Zhu, Q., Kannan, D.: Analysis of third party reverse logistics provider using interpretive structural modeling. Int. J. Prod. Econ. 140, 204-211 (2012)

14. Skyttner, L.: General systems theory: origin and hallmarks. Kybernetes 25, 16-22 (1996)

15. Ackoff, R.L.: Creating the corporate future: Plan or be planned for. Wiley (1981)

16. Yourdon, E.: Modern Structured Analysis. Yourdon Press, Prentice-Hall International, Englewood Cliffs, New Jersey (1989)

17. Akçalı, E., Çetinkaya, S., Üste, H.: Network Design for Reverse and Closed-Loop Supply Chains: An Annotated Bibliography of Models and Solution Approaches. Networks, 231-248 (2009)

18. Fleischmann, M., Krikke, H.R., Dekker, R., Flapper, S.D.P.: A characterisation of logistics networks for product recovery. Omega 28, 653-666 (2000)

19. Savaskan, R.C., Bhattacharya, S., Van Wassenhove, L.N.: Closed-Loop Supply Chain Models with Product Remanufacturing. Manage. Sci. 50, 239-252 (2004)

20. Senthil, S., Srirangacharyulu, B., Ramesh: A Decision Making Methodology for the Selection of Reverse Logistics Operating Channels. Procedia Eng. 38, 418-428 (2012)

21. Östlin, J., Sundin, E., Björkman, M.: Importance of closed-loop supply chain relationships for product remanufacturing. Int. J. Prod. Econ. 115, 336-348 (2008)

22. Seitz, M.A., Peattie, K.: Meeting the Closed-Loop Challenge: Calif. Manage. Rev. 46, 74-90 (2004)

23. Bulmuş, S.C., Xhu, S.X., Teunter, R.: Capacity and production decisions under a remanufacturing strategy. Int. J. Prod. Econ. 145, 359-370 (2013)

24. Xiong, Y., Zhou, Y., Li, G., Chan, H.-K., Xiong, Z.: Don't forget your supplier when remanufacturing. Eur. J. Oper. Res. 230, 15-25 (2013)

25. Meade, L., Sarkis, J.: A conceptual model for selecting and evaluating third-party reverse logistics providers. Supply Chain Manag. An Int. J. 7, 283-295 (2002)

26. Blackhurst, J., Dunn, K.S., Craighead, C.W.: An Empirically Derived Framework of Global Supply Resiliency. J. Bus. Logist. 32, 374-391 (2011)

27. Simatupang, T.M., Sridharan, R.: The Collaborative Supply Chain. Int. J. Supply Chain Manag. 13, 15-30 (2002)

28. Simatupang, T.M., Wright, A.C., Sridharan, R.: Applying the theory of constraints to supply chain collaboration. Supply Chain Manag. An Int. J. 9, 57-70 (2004)

29. Sarkis, J.A.: boundaries and flows perspective of green supply chain management. Supply Chain Manag. An Int. J. 17, 202-216 (2012)

30. Pokharel, S., Mutha, A.: Perspectives in reverse logistics: A review. Resour. Conserv. Recycl. 53, 175-182 (2009)

31. Krikke, H., Hofenk, D., Wang, Y.: Revealing an invisible giant: A comprehensive survey into return practices within original (closed-loop) supply chains. Resour. Conserv. Recycl. 73, 239-250 (2013)

32. Whitten, G.D., Green Jr., K.W., Zelbst, P.J.: Triple-A supply chain performance. Int. J. Oper. Prod. Manag. 32, 28-48 (2012)

33. Frohlich, M.T., Westbrook, R.: Arcs of integration: an international study of supply chain strategies. J. Oper. Manag. 19, 185-200 (2001) 
34. Cao, M., Zhang, Q.: Supply chain collaboration: Impact on collaborative advantage and firm performance. J. Oper. Manag. 29, 163-180 (2011)

35. Sarkis, J., Zhu, Q., Lai, K.: An organizational theoretic review of green supply chain management literature. Int. J. Prod. Econ. 130, 1-15 (2011)

36. Bell, J.E., Mollenkopf, D., Stolze, H.J.: Natural resource scarcity and the closed-loop supply chain: a resource-advantage view. Int. J. Phys. Distrib. Logist. Manag. 43, 351-379 (2013)

37. Flynn, B.B., Huo, B., Zhao, X.: The impact of supply chain integration on performance: A contingency and configuration approach. J. Oper. Manag. 28, 58-71 (2010)

38. Schultmann, F., Zumkeller, M., Rentz, O.: Modeling reverse logistic tasks within closedloop supply chains: An example from the automotive industry. Eur. J. Oper. Res. 171, 1033-1050 (2006) 